
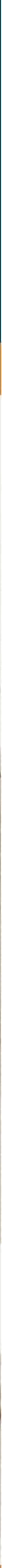



\section{REFLEXIÓN TEÓRICA EN TORNO A LOS CONCEPTOS DE CIUDADANÍA, CULTURA POLÍTICA Y DEMOGRACIA'}

(Recepción: Mayo 31 de 2013- Aceptación: Agosto 6 de 2013)

Carmenza Báez Solano*, Gilberto Bonilla Sánchez**, Álvaro Pico Duque***, Pedro Elías Ramírez Bustos****, Elurbin Romero Laguado*****

\section{Resumen}

El tema escogido para este artículo hace parte de un gran corpus temático, el de la política que de una manera directa y sistémica permea el día a día de las actividades humanas y que, además, inciden categóricamente en su desarrollo social, me refiero a que las tres categorías abordadas aquí (ciudadanía, cultura política y democracia) hacen parte inmanente de la vida y las actividades del Hombre.

\section{Palabras clave}

Ciudadanía, Cultura política, Democracia, Participación ciudadana.

\section{THEORETICAL REFLECTION AROUND THE CONGEPTS OF GITIZENSHIP, POLITIGAL GULTURE AND DEMOCRACY}

\section{Alsstract}

The theme chosen for this article is part of a large thematic corpus, that of a policy that directly and permanently permeates everyday human activities and also affects categorically their social development, I mean, that the three categories addressed here (citizenship, political culture and democracy) are part of the immanent life and activities of man.

\section{Keywords}

Citizenship, Culture, Democracy, Civic participation.

1 El presente artículo es producto del proyecto de investigación institucional que lidera el grupo de investigación “Quorum” del Departamento de Humanidades de las UTS (Unidades Tecnológicas de Santander), que se encuentra en la fase de recolección y análisis de datos.

* Docente de Tiempo Completo del Departamento de Humanidades de las UTS, Lic. en Educación de la UNAB y Esp. en Gerencia Pública de la UIS, Historiadora de la UIS, (c) a Mg. en Tecnologías educativa y medios innovadores para la educación de la UNAB-TEC Monterrey, carbaez15@ hotmail.com

** Docente de Hora Cátedra del Departamento de Humanidades de las UTS, Filósofo y Mg. en Pedagogía de la Universidad Industrial de SantanderUIS, gbonillasan@hotmail.com

*** Docente de Tiempo Completo del Departamento de Humanidades de las UTS, Filósofo de la U. San Buenaventura- Bogotá, Esp. en Desarrollo intelectual y formación y educación, UNAB-Instituto Alberto Merani -Bogotá, Mg. en Educación de la Universidad Javeriana-UNAB, alpidu@ yahoo.es

**** Coordinador Departamento de Humanidades UTS, Historiador de la Universidad Industrial de Santander UIS, Mg. En Historia Política. UIS, (c) Doctor en Historia y Política Moderna. Universidad Pablo Olavide, Sevilla España. perbus23@hotmail.com

***** Docente de Hora Cátedra del Departamento de Humanidades de las UTS, Historiador y Mg. en Historia de la Universidad Industrial de Santander-UIS, elurbin@gmail.com 


\section{Introducción}

Dentro del amplio panorama de las ciencias sociales se hace notable el interés particular en los últimos años por los fenómenos ligados a la política, particularmente los relacionados con la juventud y las vinculaciones de esta importante franja poblacional con temáticas de ciudadanía, cultura política y democracia. El presente artículo reflexivo presenta los resultados parciales del proyecto de investigación: Concepciones y vivencias de la ciudadanía y la cultura política de los estudiantes de las Unidades Tecnológicas de Santander-UTS desarrollado por el grupo de investigación QUORUM en la línea de investigación de cultura política y sociabilidad que lideran los docentes del Departamento de Humanidades de las UTS y que en esta primera fase abordó desde una perspectiva analítica e interpretativa los principales autores o referentes sobre las categorías mencionadas. Este proyecto, que cuenta con el apoyo institucional, se encuentra en la fase de recolección de datos y pretende ofrecer en otra ocasión los resultados estadísticos obtenidos a la comunidad científica y académica.

Así, el tema que se va a desarrollar es el de explicar los distintos aspectos vinculados a las variables "ciudadanía" y "democracia". A partir de estas consideraciones, lo pretendido aquí es reparar cuáles son los significados de la teoría social en relación a estos conceptos y cómo se establece una relación entre ciudadanía, cultura política y democracia por parte de la juventud de las UTS hoy en día.

\section{Acerca de la ciudadanía}

El concepto de ciudadanía política ha sido aplicado y reconstruido a lo largo de varias etapas de la historia de los países latinoamericanos y de la Europa moderna y antigua; su aplicación y reconstrucción se hicieron necesarias a raíz de las transformaciones sufridas por las sociedades en cuanto a su organización política, la extensión del territorio y la participación del individuo en los mecanismos de representación del Estado; desde Aristóteles en la Grecia clásica hasta Chantal Mouffe en la actualidad, la ciudadanía política ha sido un tema de largo alcance y de profundas raíces en la formación de las naciones.

Antes de entrar en materia con respecto al concepto de ciudadanía es necesario remitirse a los griegos, por ser ellos los primeros en formular dicha idea. Según Aristóteles, la pertenencia a la "polis" o comunidad y la participación en ella, constituyen una condición necesaria para el desarrollo del carácter bueno "entre los ciudadanos en el pleno sentido de la palabra". Para el filósofo griego, la educación contribuyó en que cada persona se considerara a sí misma como "miembro de la ciudad"; considerarse de este modo es relevante para el joven ciudadano griego, ya que:

El ser ciudadano es para las concepciones griegas un acto consciente de voluntad del joven ciudadano, pero también de los restantes ciudadanos [...], un acto de voluntad por el que el joven entra en la comunidad y es admitido por ella: no algo natural que va implícito en el nacimiento o determinado incluso por el lugar de residencia (Knauss, 1979, p.72).

La profunda significación que han tenido estas concepciones griegas, se han ligado a la experiencia histórica, y es posible afirmar, entonces, que la plena participación es un afán del joven ciudadano en la república moderna y contemporánea. Con una ligera y profunda diferencia: en sus percepciones de la ciudadanía se evidencia cómo la ciudadanía política moderna obedece a valores y contenidos prácticos que son otorgados y enseñados por los 
educadores o las instituciones en sus programas de Ciencias Sociales y Humanas; la formación de la voluntad política se convierte en una especie de salida de la minoría de edad, que no es precisamente el producto de un valerse por sí mismo (como sugeriría la concepción kantiana de la llustración), ni mucho menos el desenlace de un deseo de intervenir en el Estado (como responsable de él y preocupado en su construcción), obedece más bien al interés de robustecer su cultura política en la necesidad de mejorar el país.

La imagen de la ciudadanía política es, entonces, la de una "deficiencia" y su expresión se reconoce, en que los jóvenes admiten "que son ingenuos en asuntos de política". Es decir, a diferencia del joven político griego el joven universitario de hoy, concibe estos asuntos de la ciudadanía y la democracia, como un acto de formación y no para probar su destreza y mostrar luego sus facultades en la asamblea popular, tal como lo haría el joven político griego (Knauss, 1979, p.73).De acuerdo a Nussbaum, “la plena participación en una polis (ciudad) que funcione debidamente, es condición necesaria para el desarrollo y ejercicio de las excelencias (o virtudes) del individuo" (1995, p.89). Dichas virtudes se deben entender, según Eduardo Rueda, investigador titular del Instituto de Bioética de la Universidad Javeriana, como:

El conjunto de las formas del actuar humano que resultan más apropiadas para responder a las diversas circunstancias generales de la vida. Se consideran las más apropiadas porque garantizan la plenitud: el florecimiento de aquellos modos de ser que aseguran la realización de la mejor de las vidas posibles (Rueda, 2010, p.6).

En concreto, la participación en la ciudad, la ciudadanía o el ser ciudadano, permite que las personas cultiven su sentido de la justicia como la más perfecta de las excelencias. Bajo este punto de vista, la justicia es condición necesaria para la realización del resto de las virtudes. Que los ciudadanos cultiven el sentido de la justicia permite que las relaciones entre ellos sean equitativas y recíprocas. En otras palabras, en la concepción griega la ciudadanía era la condición de posibilidad que tenían los hombres para el desarrollo de sus virtudes y la integralidad de su ser, en su calidad de polítes que participa activa y pasivamente en el gobierno.

Aristóteles considera la ciudad como un espacio plural y dicha pluralidad característica de la existencia ciudadana aumenta la posibilidad que se presenten conflictos y desacuerdos. Lo anterior no se debe considerar como una falencia o desventaja de las sociedades y las democracias contemporáneas, al contrario, todo el pensamiento en torno a la ciudadanía y la política que a partir de la concepción griega se ha generado, invita a considerar la pluralidad y los conflictos que desata, como una condición propicia para la proliferación y vigor de la vida política que se desarrolla en el seno de la ciudad. De manera recíproca, la autora española Adela Cortina define la ciudadanía como

Un tipo de relación que tiene una dirección doble: de la comunidad hacia el ciudadano y del ciudadano hacia la comunidad. Sin duda el ciudadano asume unos deberes con respecto a la comunidad y, en consecuencia, debería asumir activamente sus responsabilidades con ellas, aspecto que el Estado de bienestar ha cuidado poco. (Cortina, 1997, p.55).

Desde otro contexto, la autora belga, Chantal Mouffe (1999), propone que la cuestión de la identidad política es decisiva y que el intento de construir identidades de "ciudadanos" es una de las tareas importantes de la política democrática actual. Según la autora 
hay muchas maneras de concebir la ciudadanía y en su discusión se juegan problemas vitales para el desarrollo de la sociedad contemporánea (p.102). A partir de lo anterior, es saludable aclarar que el modo de definir la ciudadanía está íntimamente ligado al tipo de sociedad y de comunidad política que queremos. ¿Cómo deberíamos entender la ciudadanía cuando nuestra meta es una democracia radical y plural? Semejante proyecto requiere la creación de una cadena de equivalencias entre luchas democráticas y, en consecuencia, la creación de una identidad política común entre sujetos democráticos. Lo anterior, es bastante utópico en cuanto al sentido pragmático de la política, pues para Mouffe, la ciudadanía que propone rechaza la idea de una definición universalista abstracta de particularidad y de diferencia. Considera que, "aunque sin duda la idea moderna de ciudadano fue radical para la revolución democrática, hoy en día, es un obstáculo para su extensión" (p.103), como lo confirman algunas pensadoras feministas, cuando afirman que el dominio público de la ciudadanía moderna se basó en la negación de la participación de las mujeres.

La autora contrapone a la idea del ejercicio de la ciudadanía que consiste en adoptar un punto de vista universal, asimilado a la razón y reservado exclusivamente a los hombres; con el ejercicio de la ciudadanía que "consiste en identificarla con los principios éticopolíticos de democracia moderna y que puede haber tantas formas de ciudadanía como interpretaciones de esos principios" (1999, p.104). Dentro de esta corriente, denominada por algunos como neo-marxismo, y por la propia autora como democracia radical, hacer una distinción entre lo privado (libertad individual) y lo público, se mantiene, al igual que la distinción entre el individuo y el ciudadano, pero corresponden a esferas discretas separadas. Esas dos identidades existen en una tensión permanente e imposible de reconciliar; tensión entre la libertad e igualdad que caracteriza a la democracia moderna y, por esta razón, la ciudadanía de las democracias radicales, aprovecha la tensión entre estos dos principios, pero además la tesis de Mouffe, ha permitido conocer otra manera susceptible de pensar en la alteración y salida de la crisis de la democracia, y señalar:

(...) que el ideal de ciudadanía podría contribuir enormemente a la extensión de los principios de libertad e igualdad. Combinando el ideal de derechos y pluralismo y las ideas de inspiración pública y preocupación ético-política, una nueva concepción democrática de ciudadanía podría restaurar la dignidad a lo político y proporcionar el vehículo de la construcción de una hegemonía democrática radical (1999, p.105).

Por lo demás, con respecto a las limitaciones que presenta la concepción moderna de ciudadanía, Mouffe, argumenta que éstas no van a superarse "si en su definición se vuelve políticamente relevante la diferencia sexual, sino al construir una nueva concepción de ciudadanía en la que la diferencia sexual se convierta en algo efectivamente no pertinente" (1999, p.118); esto, por supuesto, requiere de una concepción de la agencia humana que permita la articulación de un conjunto de posiciones de sujeto, correspondientes a la multiplicidad de las relaciones sociales en que se inscribe. Esta multiplicidad se construye dentro de discursos específicos que no están relacionados necesariamente, sino que tienen formas de articulación contingentes y precarias. Con exactitud y de manera más explícita dice Mouffe:

No hay razón para que la diferencia sexual tenga que ser pertinente en todas 
las relaciones sociales. Desde luego, hoy en día existen muchas prácticas, discursos e instituciones diferentes que construyen (diferencialmente) a los varones y a las mujeres y la distinción masculino/ femenino existe como una distinción pertinente en muchos campos. Pero esto no quiere decir que así tenga que seguir siendo, y nos podemos imaginar perfectamente bien la posibilidad de que la diferencia sexual se convierta en algo irrelevante en muchas de las relaciones sociales en que actualmente es relevante. De hecho, éste es el objetivo de muchas de las luchas feministas (1999, p.118).

No quiere decir lo anterior que para Mouffe haya necesidad de desaparecer la diferencia sexual como una distinción pertinente entre hombres y mujeres, tampoco que la igualdad entre ellos requiera de relaciones sociales neutras desde el punto de vista del género, pues como se ha logrado evidenciar, en muchos casos, tratar a hombres $y$ mujeres de igual forma implica tratarlos de manera diferente. Pues como ella misma afirma su tesis es que en el dominio de lo político y por lo que toca a la ciudadanía, la diferencia sexual no debe ser una distinción pertinente.

La autora, dice estar de acuerdo con las críticas que se han construido contra la concepción liberal, masculina, de la ciudadanía moderna, pero, cree que

un proyecto de democracia radical y plural no necesita un modelo de ciudadanía sexualmente diferenciado en el que las tareas específicas de hombres y mujeres sean valoradas con equidad, sino una concepción verdaderamente diferente de qué es ser un ciudadano y de cómo actuar como miembro de una comunidad política democrática (Mouffe, 1999 p.119).

Los problemas que presenta la concepción liberal de ciudadanía no se agotan con la lucha feminista por restituir sus derechos y deberes en las sociedades contemporáneas que estimulan la dominación masculina. De igual forma piensa Thomas Humphrey Marshall (1998), cuando afirma que la ciudadanía se entiende como la condición de quienes pertenecen a una comunidad, dicha condición implica, igualdad de derechos y deberes para los ciudadanos e implica participación; afirmación que complementa Adela Cortina cuando afirma que un ciudadano es:

Aquel que pertenece a una comunidad política, con la que tiene contraídas unas especiales obligaciones de lealtad. La noción de "pertenencia" no sólo encierra un sentimiento de arraigo en una comunidad política concreta, sino también la conciencia de tener con respecto a esa comunidad responsabilidades, obligaciones de lealtad (2001, p.119).

A la postre Mouffe propone, entonces, una visión de democracia radical y plural que entiende la ciudadanía como "una forma de identidad política que consiste en la identificación con los principios políticos de la democracia moderna pluralista, es decir, en la afirmación de la libertad y la igualdad para todos" (1999, p.120). Según la autora, dicha identidad o ciudadanía, tendría que ser "una identidad política común entre personas comprometidas en muy diversas empresas y con diferentes concepciones del bien, pero vinculadas las unas a las otras por su común identificación con una interpretación dada de un conjunto de valores ético-políticos" (Mouffe, 1999), pues la ciudadanía no es sólo una identidad entre otras, como en el liberalismo, ni es la identidad dominante que anula a todas las demás, como en el republicanismo cívico. Es, en cambio, "un principio articulador que afecta a las diferentes posiciones de sujeto del agente social al tiempo que permite una pluralidad de lealtades específicas y el respeto de la libertad individual" (Mouffe, 1999, p.120). La ciudadanía de la democracia radical y 
plural, exige cambios profundos en las bases de la sociedad contemporánea, que está cimentada sobre la "eternización de lo arbitrario" (Bourdieu, 2000, pp.79) y problemáticas que emanan de las complejas relaciones entre los individuos en comunidad.

Al margen de estas observaciones puntuales del campo filosófico y la teoría social, también encontramos distintas investigaciones que se han desarrollado con respecto a la ciudadanía a nivel internacional, podemos encontrar el importante estudio realizado por la Asociación Internacional para la Evaluación del Logro Educativo (IEA), que contó con el apoyo económico de Estados Unidos y Alemania. En 1971 la IEA condujo un estudio de diseño cuantitativo en educación cívica en el que empleó muestras representativas nacionales de tres grupos de edades en la República Federal de Alemania, Finlandia, Irlanda, Israel, Italia, Países Bajos, Nueva Zelanda, Suecia y Estados Unidos. Cerca de 30.000 estudiantes respondieron los instrumentos que medían conocimientos y actitudes, mientras que 5.000 profesores y 1.300 directores y rectores describieron la pedagogía y las características de las escuelas (IEA, 1994).

Dos décadas después, la IEA propuso un nuevo estudio de educación cívica que inició en el año de 1994 con la aprobación de su Asamblea General debido al interés de muchos de sus países miembros, quienes experimentaban transiciones políticas, económicas y sociales. Dicho estudio se llevó a cabo en veintiocho países de 51 miembros que recibieron la invitación para participar en la prueba y en la encuesta realizada en dos fases. Este estudio investigativo en dos fases intentó informar y estimular la discusión entre diseñadores de políticas, ejecutores de currículo, profesores, formadores de profesores, investigadores y público en general, $y$, de igual modo intentó profundizar en la comprensión de las posibilidades y prácticas de la educación cívica tal como se realiza en diferentes contextos. Así, los resultados obtenidos en esta investigación han enriquecido la comprensión de lo que los jóvenes saben acerca de la democracia, la ciudadanía, la identidad nacional y la diversidad, y ha desarrollado la mayoría de las preguntas de política con las cuales se empezó el estudio.

En otro contexto, los Institutos de Estadística (INES) de Francia, Suecia y Canadá realizan estudios dirigidos hacia temas como la participación electoral; intermitencia del voto (votantes sistemáticos y abstencionistas sistemáticos), los cuales han servido de referencia para quienes indagan sobre la ciudadanía y sus implicaciones en temas electorales. Otro gran aporte lo realizó el Proyecto de Opinión Pública de América Latina (LAPOP),

considerado uno de los ejemplos más exitosos en la generación de este tipo de investigaciones, pues cuenta con una periodicidad anual que permite realizar análisis comparativos de los cambios de percepción política que se presentan en los diferentes países de Latinoamérica y en otras regiones como Norteamérica, Europa y África" (Departamento Administrativo Nacional de Estadística-DANE, 2009, p.22).

Por otra parte, se encuentra el trabajo que desarrolla la Corporación Latino barómetro, que funciona como una corporación de derecho privado sin fines de lucro, con sede en Santiago de Chile. Este colectivo tiene la responsabilidad de llevar a cabo el estudio, tanto en la ejecución del proyecto como en la distribución de los datos. El Latinobarómetro funciona a través de la aplicación anual de una encuesta en 18 países de la región, "aplicando un cuestionario idéntico, con una unidad metodológica y técnica que permite 
la representación de las opiniones, actitudes, comportamientos y valores de los universos medidos" (DANE, p.23)

Asimismo, se pueden mencionar los avances investigativos del Proyecto Colectivo de Enlace: Desarrollo de Competencias Ciudadanas en Estudiantes Universitarios, formulado en el año 2006 en el marco del proyecto Atlantea (Proyecto Atlantea, Universidad de Puerto Rico, UPR, 2006), que dirige el profesor Ángel Villarini, en el que participan Cuba, Colombia, República Dominicana, Estados Unidos, Venezuela y Aruba, su trabajo se enfoca específicamente a la población universitaria de esta región. Dicha investigación se constituye como uno de los estudios más recientes sobre el tema que plantea el presente estudio en el marco latinoamericano. El proyecto tiene entre sus principales objetivos realizar un diagnóstico sobre competencias (conceptos, destrezas y actitudes) de los estudiantes en torno a la participación ciudadana y las competencias ciudadanas, elaborar un modelo de educación universitaria en competencias ciudadanas y la construcción de una propuesta de certificación en educación ciudadana para la educación superior.

\section{Acerca de la cultura política}

La categoría analítica de cultura política es uno de los tres conceptos más novedosos de las tres nociones abordadas aquí y quizá su aproximación reflexiva sirva para entender las distintas posibilidades que tiene la sociedad civil con relación a la esfera política.

Una razón para relacionar este concepto con el concepto de ciudadanía es la necesidad de reconocer la cercanía de la cultura política en los componentes de la tradición política latinoamericana y, por ende, con la gramática política de la sociedad en general. Podría afirmarse, con cierto grado de precisión, que es imposible radicalizar los valores de la justicia y los contenidos prácticos de la democracia y la ciudadanía de la democracia plural, mientras los ejes de la cultura política de los pueblos latinoamericanos aparecen aún propensos a enajenar que a delegar el poder en sus dirigentes elegidos, proposición que sirve para explicar la inestabilidad de América Latina (Morse, 1995, p.199).

Cabe señalar, al mismo tiempo, que al universo de la cultura política corresponden aspectos formales y noformales inherentes a la participación política y la participación social de los miembros de cualquier sociedad; aspectos como: la legislación electoral, las elecciones, el papel político de la prensa, los partidos políticos, los programas políticos, la clientela y la maquinaria política, el fraude y la violencia política derivada de los procesos electorales, entre otros. Todos estos elementos que sumados al conjunto de valores, principios, tradiciones y costumbres (Cultura) que animan la vida de un pueblo y que se expresan en la formalidad y en la informalidad institucional.

La vivencia de la cultura política está relacionada con un contexto histórico determinado. La complejidad de la sociedad contemporánea hace que la vivencia de la cultura política plantee nuevos desafíos a los ciudadanos que reconocen su responsabilidad frente a la consolidación de la democracia como forma de gobierno, la legitimación del sistema politico y el fortalecimiento de los valores y actitudes democráticos en los ciudadanos.

La primera fase de la tradición culturalista en el estudio de la política abarca la década de los cuarenta a los cincuenta. Este periodo es denominado la escuela de "cultura y personalidad" cuyos principales exponentes son Rut Bebedict, Margaret Mead, Erich 
Fromm y Harold Laswell. Las tesis que predominan en esta etapa son el resultado de una síntesis de las ideas de la antropología cultural y del psicoanálisis, a partir de los cuales se intenta explicar comportamientos políticos y fenómenos como el autoritarismo y el fascismo en fusión de la socialización de patrones de conducta aprendidos en la familia durante la niñez (Krotz, s.f.).

Al hablar de cultura política es ineludible destacar el aporte que hizo en los años sesenta la tradición EstructuralFuncionalista de escuela politológica norteamericana, estudio de la "civic culture" y es importante mencionar los trabajos de Gabriel Almond, G. Bingham Powell y Lucian Pye, teóricos de ciencia política, pioneros en la utilización del concepto integrado a un contenido temático. Para Powell, en el texto Cultura política comparada, la cultura política como variable se sintetiza como "el actuar del hombre, culturalmente definido, en política" (Almond y Powell, 1972); actuar que está potenciado por todos y cada uno de aquellos elementos que le facilita su cultura para incursionar en sus más variados ambientes. Estos parámetros orientan el comportamiento de los ciudadanos hacia el sistema político; para ampliar esta idea se plantea la diferencia entre estructura referida a todas las actividades visibles del sistema político y cultura política asumida como las dimensión psicológica del sistema político. Por su parte Verba, define la cultura política como "el sistema de creencias empíricas y símbolos expresivos y valores que definen la situación en que una acción política se desarrolla" (Verba, 1963, p.234).

La idea de cultura política es desarrollada en la investigación politológica por G. Almond, el marco de la modernización y de la transición de sociedades tradicionales a sociedades modernas. Desde esta escuela, la cultura política es definida como

el patrón de actitudes individuales y de orientación con respecto a la política para los miembros de un sistema político. Es el aspecto subjetivo que subyace en la acción política y le otorga significados. Tales orientaciones individuales incluyen diversos componentes: a) orientaciones cognitivas, conocimiento preciso -o no- de los objetos políticos y de las creencias; b) orientaciones afectivas, sentimientos de apego, compromisos, rechazos y otros similares respecto de los objetos políticos, y c) orientaciones evaluativas, juicios y opiniones sobre los aspectos políticos que, por lo general, suponen la aplicación de determinados criterios de evaluación a los objetos y acontecimientos políticos. (Almond, 1956).

Para Gabriel Almond y Sidney Verba es claro que los países-modelo en cuanto al desarrollo alcanzado por la "civic culture" son Inglaterra y Estados Unidos, Suiza y los países escandinavos:

La participación política desarrolla un conjunto de actitudes específicas con respecto a las estructuras políticas de insumo (partidos y grupos de intereses) y al papel que pueden desempeñar los individuos en esas estructuras. En tal caso, el individuo ha alcanzado un nivel de secularización cultural (o especificidad), con el cual estamos familiarizados quienes vivimos en el sistema democrático. Claro está que aún en los sistemas políticos más modernos y secularizados existen individuos que nunca han alcanzado ese nivel de orientación. Sin embargo, en naciones como Inglaterra, los países escandinavos, Estados Unidos y Suiza, una proporción muy grande de la población ha alcanzado ese nivel. A medida que se extiende la alfabetización es probable que se desarrolle también una creciente especificidad de orientación" (Almond y Verba, 1963, p.234). 
Esta tradición teórica y de investigación da a la variable de cultura política, en términos metodológicos, un uso ampliamente funcional, que puede dar cuenta del fenómeno en distintas sociedades, y que pueda dar lugar a trabajos de análisis de cultura política comparada en distintos escenarios nacionales. Esta tradición considera que la cultura política no es una categoría de explicación residual; comprende un conjunto de fenómenos que pueden ser identificados $y$, hasta cierto punto, medidos culturales como realidades sociales autónomas y no como un simple epifenómeno de la economía o de la política; muestra un avance importante en el intento de construir una definición operativa capaz de ser sustentada en datos empíricos extraídos de la realidades culturales estudiadas y destaca aspectos importantes del cambio cultural y político en los procesos de transición de las sociedades tradicionales a las modernas.

Resulta igualmente importante para este artículo presentar el concepto cultura política propuesto por la escuela Turinesa, especialmente en los aportes dados por Norberto Bobbio y Michelangelo Bovero que en dos textos: Diccionario Político y Origen y Fundamento del Poder Político hacen referencia a cultura política como una categoría de análisis novedosa que define una dimensión cultural de la política, es decir, que para Norberto Bobbio la cultura política es una categoría que se refiere a orientaciones específicamente políticas con relación al sistema político y sus distintas partes; $y$ a actitudes relacionadas con el rol del yo en el sistema, esto equivale a decir que, en cualquier sistema político hay un reino subjetivo ordenado de la política que da sentido a las decisiones políticas, disciplina a las instituciones y da significado a los actos individuales. Desde esta perspectiva: “El término cultura política se usa para designar el conjunto de actitudes, normas y creencias, compartidas más o menos ampliamente por los miembros de una determinada unidad social, y que tienen como objeto los fenómenos políticos" (Matteuchi,1991, p.470).

La perspectiva antropológica de la cultura política repara en las articulaciones entre política y vida cotidiana y desde un interés por los escenarios locales de la política, se evidencian que los sentidos acerca de la política construidos desde los espacios locales, no siempre van en la misma dirección de las concepciones formales, institucionales, racionalistas y universalistas que presiden frecuentemente la formulación y aplicación de las políticas públicas de modernización, participación e integración políticas. Es importante destacar que los estudios de cultura política que se enfocan en visión antropológica de la cultura logran ser aplicables al estudio de formas locales de cultura política. Los estudios realizados desde la antropología política introducen inevitablemente un supuesto de valor relativamente extraño al propio universo de estudio; el de la jerarquía entre los aspectos culturales de integración en el orden legítimo y todos aquellos que no conducen de forma necesaria a tal integración, sino que responden a condiciones locales de existencia. Desde esta perspectiva los usos del concepto de cultura política, se amplían para incorporar los aspectos formales e informales de la cultura que son significativos a la hora de abordar el estudio de cualquier sociedad en el pasado o en el presente.

En esta línea, hay unos muy bien logrados estudios sobre cultura política que evidencian la dimensión del término, especialmente los estudios de Natalie Zemon Davis, Cultura política en la temprana Edad Moderna. Y el trabajo del profesor Clifford Geertz titulado Negara. El Estado: Teatro en Bali del siglo XIX 
(2000). Trabajo en el que además de hacer un detallado análisis de la cultura política balinesa, desde un enfoque propiamente de antropología política, contiene un valiosísimo método histórico, que en lo que respecta a cultura política puede ejemplificar la utilidad del uso de la categoría cultura política en las distintas ciencias sociales.

Geertz sostiene que "la politica de un país refleja el sentido de su cultura". Hacer inteligible la vida política al concebirla conformada por una serie de concesiones -ideales, hipótesis y juicios- derivadas de preocuaciones que trasciende en mucho dicha vida política, y dar realidad a esas concesiones viéndolas, no en un diáfano mudo de formas mentales, sino en lo concreto e inmediato de las luchas. Aquí, cultura son las redes de significación en virtud de las cuales los hombres dan significación a su existencia y la política es uno de los escenarios en los que se desenvuelven públicamente dichos sentidos de su cultura (Geertz, 1987, p.262).

Es igualmente importante referenciar los trabajos de Ernest Gellner Cultura e identidad y política: El Nacionalismo y los nuevos cambios sociales; Óscar W. Gabriel Cambio social y cultura Política: El caso de República Federal de Alemania; y Óscar Landi, quien menciona la amplitud de los escenarios y modalidades en los cuales se confrontan permanentemente elementos de la cultura política, al tiempo que llama la atención al carácter histórico y relacional que le es inherente; para su identificación propone someter a análisis los discursos y/o manifestaciones culturales que hablen explícitamente de política, y que permiten ampliar el marco interpretativo cultura política, por ejemplo: las creencias; el sentido común; el flujo informativo; las prácticas religiosas; las identidades sexuales, sociales, regionales; estilos estéticos; memorias individuales y colectivas; rituales; discursos. Estos elementos constituyen una trama de significantes diferentes que se articulan, compiten, asocian, desconectan o yuxtaponen en los conflictos por el sentido del orden con que los individuos vivimos nuestras relaciones sociales (Landi, 1988).

Este conjunto de textos enfatizan en el manejo de cultura política y cuya pertinencia permiten identificar, que con la variable cultura política, es posible iluminar cualquier referente histórico o circunstancial, incluso el de las concepciones y vivencias de la ciudadanía de los estudiantes universitarios UTS.

En el contexto colombiano, las Ciencias Sociales y particularmente la investigación histórica han atendido de manera muy escasa y parcial este campo de estudio, ya que a este respecto las investigaciones son aisladas y poco orgánicas. Lo anterior obliga a revisar los aspectos importantes, particularmente de la historiografía política sobre el siglo XIX, que, aunque no aborden el tema de manera directa, ilustran características fundamentales relacionadas con la cultura política colombiana; además de dar cuenta de cómo efectivamente ocurrieron los procesos, estos textos son importantes porque dan valiosas pistas, (fuentes primarias y secundarias) a partir de ellas es posible precisar los alcances y las limitaciones de dichas investigaciones con respecto al uso de esta categoría analítica.

Durán J. A. en Para una hermenéutica de la cultura política señala que en el contexto latinoamericano se empieza hablar de cultura política, desde inicios de los años 80 y más acentuadamente en los años 90, primero en América Latina y un poco más tarde en Colombia. En este mismo texto Durán señala que hablar de cultura política es posible si, la categoría se asume desde la cultura, entendida como el "cultivo" de los 
valores de una sociedad en torno a lo estrictamente político (Durán, 1993, p.23). $Y$ en este sentido, la cultura política no sólo como tradición sino como concepto fundamental aparece, cada vez, más necesario en la explicación del tema de la ciudadanía y la democracia que caracteriza y define la percepción de los jóvenes contemporáneos en su relación con el Estado, el gobierno y la política de hoy.

\section{Acerca de la Democracia}

En una época caracterizada por crisis y vaivenes en los regímenes políticos, por la ubicación de la democracia como el tema central del debate político a nivel mundial y por la incidencia de la globalización como elemento que permea la continuidad del Estado-nación, es necesario cerrar esta reflexión y comparar las apreciaciones que sobre el tema consolidan algunos autores sobre la permanencia en el tiempo de la democracia y, en especial, su incidencia en las sociedades humanas actuales.

A partir de la acepción del término (Democracia) en la antigua Grecia, y que fue acuñado en Atenas en el siglo $\mathrm{V}$ a. C., se puede llegar a la estimación de su significado como algo más complejo, puesto que este término ha cambiado con el tiempo, por la sucesiva introducción del Estado moderno, la modernidad política y aspectos puntuales, como el reconocimiento del voto femenino en el siglo $X X$ y los avances tecnológicos, en el intrincado estatuto de los sistemas, redes, virtualidad y sensorialidad, como la tercera gran revolución en la historia de la humanidad y del mundo contemporáneo.

Cuando Aristóteles en la Grecia Clásica se refiere a la democracia, afirma:

La primera forma de democracia es la que se funda principalmente en la igualdad. Y la ley de tal democracia entiende por igualdad que no sean más en nada los pobres que los ricos, que ni dominen los unos sobre los otros, sino que ambas clases sean semejantes. Pues si la libertad, como suponen algunos, se da principalmente en la democracia, y la igualdad también, esto podrá realizarse mejor si todos participan del gobierno por igual y en la mayor medida posible. Y como el pueblo constituye el mayor número y prevalece la decisión del pueblo, este régimen es forzosamente una democracia (Aristóteles, 2005, p.175).

De lo anterior, se entiende la influencia del concepto y la práctica de la democracia que se originó en Grecia, como determinante en las comparaciones posteriores entre la democracia directa y la democracia indirecta. Habría que decir también cómo las anteriores consideraciones se relacionan con el concepto que al respecto genera la reflexión de Carpizo, quien afirma:

Democracia es el sistema en el cual los gobernantes son electos periódicamente por los electores; el poder se encuentra distribuido entre varios órganos con competencias propias y con equilibrios y controles entre ellos, así como responsabilidades señaladas en la Constitución con el objeto de asegurar los derechos fundamentales que la propia Constitución reconoce directa o indirectamente (Carpizo, 2007, p.100).

Presupone este concepto "un orden jurídico, una constitución y un estado de derecho que garanticen las libertades y los derechos fundamentales de las personas" (Carpizo, 2007, p.101). En las consideraciones de Carpizo sobre la razón de ser de la democracia, expone 17 características principales que la circunscriben como un régimen que toma en cuenta la doctrina sobre la política fundamentándose en los derechos humanos, libertades, valores, principios como la vida, acciones comunitarias, actitudes y procesos de construcción y desarrollo humano. 
No estará por demás traer a colación el engranaje de cómo los elementos esenciales y funcionales de la democracia, se relacionan con el concepto que asume Bobbio:

Hago la advertencia de que la única manera de entenderse cuando se habla de democracia, en cuanto contrapuesta a todas las formas de gobierno autocrático, es considerarla caracterizada por un conjunto de reglas (primarias o fundamentales) que establecen quién está autorizado para tomar las decisiones colectivas y bajo qué procedimientos (Bobbio, 1986, p.14).

De la anterior apreciación Bobbio establece una serie de consideraciones necesarias y significativas para el ejercicio de la democracia así: Habida cuenta de quién está autorizado para tomar decisiones, él considera que se debe partir de la regla fundamental de la democracia que es la regla de la mayoría pero también afirma que: "ninguna decisión tomada por mayoría debe limitar los derechos de la minoría" (Bobbio,1986 p.27) con base en la cual se consideran decisiones colectivas $y$, por tanto, obligatorias para todo el grupo.

Es necesario, por lo mismo, que aquellos que están Ilamados a decidir o a elegir a quienes deberán decidir, se planteen alternativas reales y estén en condiciones de seleccionar entre una $u$ otra.

Una serie de derechos se les debe garantizar a los elegidos para decidir: La libertad de opinión, de expresión de la propia opinión, de reunión, de asociación y otras, los derechos mínimos con los cuales nació el Estado liberal y se construyó la doctrina del Estado de derecho, dentro de los Ilamados derechos inviolables del individuo. De ahí que el Estado liberal no solamente es el supuesto histórico sino también jurídico del Estado democrático como punto de partida para garantizar las libertades fundamentales.

Entendido lo que no ha sido la democracia, Bobbio señala unas falsas promesas: el nacimiento de la sociedad pluralista, la reivindicación de los intereses, persistencia de las oligarquías, el espacio limitado, el poder invisible, el ciudadano no educado, el gobierno de los técnicos, el aumento del aparato burocrático, el escaso rendimiento.

Para hacer más comprensible la conceptualización de democracia en el mundo contemporáneo, tomada en su esencia, siempre se la ha indicado como una entidad política, en forma de Estado y de gobierno, y así ha permanecido como la acepción originaria, y en este sentido, considerándola como un conjunto simbiótico:

(...) entre democracia política, democracia social y democracia económica siendo la primera condición necesaria de las otras. Las democracias en sentido social y económico amplían y completan la democracia en sentido político; cuando existen, son también democracias más auténticas, ya que son micro-democracias, democracias de pequeños grupos. Por lo demás, si no existe democracia en el sistema político las pequeñas democracias sociales y económicas corren el riesgo, a cada momento de ser destruidas. Por ello "democracia" sin adjetivos se entiende como democracia política. Entre ésta y las otras democracias, la diferencia es que la democracia política es supra-ordenada y condicionante, y las otras son subordinadas y condicionadas. Si falta la democracia mayor, con facilidad faltan las democracias menores; lo cual explica por qué la democracia haya sido siempre un concepto desarrollado y teorizado como sistema político (Sartori, 1993, p.8). 
Dentro de este marco ha de considerarse la importancia de la igualdad como un ethos de la democracia en cuanto que la democracia social apunta a la igualdad de estatus, la democracia política a la igualdad jurídico-político y la democracia económica a esa igualdad que tiende a eliminar los extremos de pobreza y de riqueza. Es preciso señalar la importancia y amplitud del concepto de democracia que asume Dahl, como un ideal que no alcanza ningún país.

En su teoría de la democracia fundamenta su esencia que es normativa, en la institucionalización de los valores de la libertad, la autonomía y la autodeterminación moral y la promoción de los intereses humanos compartidos a partir de tres clases de igualdad; igualdad moral intrínseca de todos los ciudadanos; la igualdad de acceso a la autonomía y la autodeterminación personal; la igualdad política definida según los cinco criterios del proceso democrático. Todo esto implica, a su vez, que las oportunidades para alcanzar tales bienes tienen que ser equitativas para todos los ciudadanos. $\mathrm{O}$, lo que es lo mismo, la democracia, en su carácter procedimental, reclama y constituye el prerrequisito de la justicia distributiva. La igualdad política es un medio indispensable para alcanzar una distribución equitativa de la libertad de oportunidades, así como oportunidades iguales para todos para la autonomía y la autodeterminación. Dahl considera las poliarquías como sistemas democráticos con cierta relatividad debido a que son estructuras substancialmente liberalizados y popularizados, muy representativos y abiertos al debate público permanente.

Por otra parte, Schumpeter resume en forma lógicamente impecable la soberanía popular y la eleva por encima de cualquier consideración en la teoría política con la siguiente definición:
El método democrático es aquel sistema institucional de gestación de las decisiones políticas que realiza el bien común, dejando al pueblo decidir por sí mismo las cuestiones en litigio mediante la elección de los individuos que han de congregarse para llevar a cabo su voluntad (Schumpeter, 1983, p.321).

Todo lo dicho hasta ahora explica e interpreta las consideraciones complejamente elaboradas del concepto de democracia que autores, de notoriedad mundial y autoridades al respecto, han realizado para la recuperación histórica de un sistema que sigue vigente en la humanidad contemporánea a pesar de los grandes cambios económicos, el crecimiento desproporcionado de la población, y los problemas mundiales como retos indiscutibles para un manejo democrático en una época de irreversibles crisis.

Bien, pareciera, por todo lo anterior, que la democracia vista en todas sus dimensiones conlleva elementos comunes desde los autores citados: los valores de la igualdad, equidad, justicia, respeto por los derechos fundamentales implícitos en lo jurídico, político, en el orden social, económico y, esto es, en esencia lo que hace de la democracia el sistema justo, con el cual la sociedad le apuesta por un mundo mejor, incluyente y pluralista.

\section{Conclusión}

La relación entre los conceptos de ciudadanía, democracia y cultura política es sustantiva al desarrollo histórico de la otrora sociedad como clave en el análisis de la sociedad actual. Es una articulación que se ha tejido, paso a paso, a la sombra de la compleja y enorme densidad de la trayectoria histórica de inestabilidad de los países latinoamericanos y en el 
horizonte del análisis político y social; esta tríada de conceptos y realidades son de importancia para explorar los problemas de la ciudadanía, los componentes de la tradición forjados históricamente por la cultura política y la estimación de la democracia, como sustento y significado para que las cosas no sigan iguales.

\section{Referencias}

Almond, G. y Powell. G. (1972). Política comparada. Buenos Aires: Editorial Paidós.

Aristóteles. (1997).Política. Madrid: Espasa Calpe.

Aristóteles. (2005). Política, Trad. de Julián Marías y María Araujo. Madrid: Centro de Estudios Políticos y Constitucionales.

Bobbio, N. (1985) La crisis de la democracia y la lección de los clásicos, en: Norberto Bobbio, Giulano Pontara y Salvatore Veca. Crisis de la democracia. Barcelona: Editorial Ariel.

Bobbio, N. (1986).El futuro de la democracia. México: Fondo de Cultura Económica.

Bourdieu, P. (2000). La dominación masculina. Barcelona: Anagrama.

Carpizo, J. (2007). Ensayo publicado en boletín Mexicano de Derecho Comparado, Nueva serie, año XL, No.119 - mayo - agosto.

Cortina, A. (2007).Ciudadanos del mundo. Hacia una teoría de la ciudadanía. Madrid: Alianza editorial.

Corina, A. (2001). Alianza y contrato. Política, Ética y Religión. Madrid: Trota.

Dahl, R. (2006). La Democracia. Una guía para los ciudadanos. Buenos Aires: Taurus.

Departamento Administrativo Nacional de EstadísticaDANE. Metodología encuesta de cultura política, Bogotá: Imprenta Nacional, 2009.

Durán, J. (1993). Para una hermenéutica de la cultura política. México: Editorial Gedisa.
Geertz, C. (1987).La interpretación de las culturas. Barcelona: Paidós.

Geertz, C. (2000). Negara, el Estado - Teatro en Bali del siglo XIX. Barcelona: Paidós.

Gellner,E. (1988). Cultura, identidad y política: el nacionalismo y los nuevos cambios sociales. Barcelona: Gedisa.

Knauss, B. (1979). La polis. Individuo y estado en la Grecia Antigua. Madrid: Aguilar.

Krotz, E. (s.f.). Antropología, elecciones y cultura política. Recuperado marzo 03 de 2013 en: jurídicas.unam. $\mathrm{mx} /$ publica/libre/rev/nuant/cont/38/cnt/cnt1.pdf

Landi, O. (1988). Cultura política: un concepto sutilmente ambiguo, en Reconstrucciones: Las nuevas formas de la cultura política. Buenos Aires: Puntosur.

Marshall, T. (1998). Ciudadanía y clase social. Madrid: Alianza editorial.

Matteucci, N. y Pasquino, G. (1991). Diccionario de Política. México: Siglo XXI editores.

Morse, R. (1995). Resonancias del Nuevo Mundo. México: Editorial Vuelta.

Mouffe, C. (1999). El Retorno de lo Político. Barcelona: Paidós.

Nussbaum, M. (1995). La fragilidad del bien. Madrid: Visor.

Proyecto Atlantea, Universidad de Puerto Rico, (2006) Buscar y encontrar en Internet [Formato HTML] http://atlantea.upr.edu/ (Consultado el 15 de marzo de 2013).

Proyecto IEA, La Educación Cívica y Ciudadana, (1994). Buscar y encontrar en Internet [formato HTML] http://www.mineducacion.gov.co/1621/ articles-85748 archivo pdf3.pdf (consultado el 29 de marzo de 2013).

Rueda, E. (2010). Ciudadanía, democracia y participación Bogotá: MEN.

Sartori, G. (1993). Qué es la democracia. México: Alianza.

Schumpeter,J. (1983). Capitalismo, Socialismo y Democracia. Barcelona: Orbis. 